\title{
Emergency Exposure Situations: IAEA Safety Standards and Guidance
}

\author{
E. BUGLOVA, T. MCKENNA, V. KUTKOV
}

\begin{abstract}
The Incident and Emergency Centre (IEC) of the International Atomic Emergency Agency (IAEA) is the global focal point for preparedness and response to nuclear and radiological incidents and emergencies irrespective of their cause. In the area of preparedness the Centre continuously works to develop standards and guidance for strengthening Member States' preparedness; practical tools and training programs to assist Member States in promptly applying the standards and guidance; and organizes a variety of training events and exercises. This paper provides an overview of the information presented in the IAEA Safety Standards and Guidance in the area of emergency preparedness and response.
\end{abstract}

Keywords: International Atomic Emergency Agency/emergency/preparedness/response/ Incident and Emergency Centre

\section{Introduction}

The expansion of nuclear power programmes, wide application of ionizing radiation, and the potential of malicious acts involving nuclear or other radioactive material require a high level of preparedness for efficient response to nuclear or radiological incidents and emergencies. The responsibility for response to such emergencies and for protection of the public, property and the environment remains with the operator at the facility level and within the affected State at the national, regional and local level. However, the Convention on Early Notification of a Nuclear Accident (Early Notification Convention) and the Convention on Assistance in the Case of a Nuclear Accident or Radiological Emergency (Assistance Convention) (IAEA, 1987) also confer specific response obligations on the IAEA. The Early Notification Convention and the Assistance Convention are the primary legal instruments that establish an international emergency preparedness and response framework. These are supplemented by a number of safety standards,

IAEA, Incident and Emergency Centre, Department of Nuclear Safety and Security, Wagramerstrasse 5, P.O. Box 100, A-1400 Vienna, Austria. 
tools, protocols and operational arrangements. Together, these instruments establish the IAEA emergency preparedness and response framework for nuclear and radiological incidents and emergencies. The IAEA discharges its role through its Incident and Emergency System (IES) consisting of a 24-hour a day contact point and an operational focal point, the IEC. The IEC is the global focal point for preparedness and response to nuclear and radiological incidents and emergencies irrespective of their cause.

\section{IAEA safety standards and guidance in the area of emergency preparedness and response}

In the area of preparedness the IEC continuously works to develop standards and guidance for strengthening Member States' preparedness; practical tools and training programs to assist Member States in promptly applying the standards and guidance; and organizes a variety of training events and exercises. The IEC is developing standards and guidance in the area of emergency preparedness and response utilizing the lessons learned from response to past radiation emergencies and from exercises (McKenna et al., 2007).

The IEC develops guidance and provides training for the following target groups (audience): decision-makers (emergency managers), emergency planners (facility, local, regional and national level), emergency response coordinators, staff of regulatory authorities, qualified experts/radiation protection officers (radiological assessors, technical advisers to decision-makers), medical personnel (responding on-site and off-site), first responders: police, fire fighters, emergency medical personnel (paramedics), civil protection personnel, persons responsible for training in emergency preparedness and response and public information officers.

In 2002 the IAEA has published the Safety Requirements Preparedness and Response for a Nuclear or Radiological Emergency (IAEA, 2002), jointly sponsored by the FAO, IAEA, ILO, OECD/NEA, PAHO, OCHA and WHO, which established the requirements for an adequate level of preparedness and response to a nuclear or radiological emergency in any State. There are two Safety Guides which support implementation of the GS-R-2 Requirements, namely, Arrangements for Preparedness for a Nuclear or Radiological Emergency, GS-G-2.1, jointly sponsored by the FAO, IAEA, ILO, PAHO, OCHA and WHO (IAEA, 2007), and Criteria for Use in Preparedness and Response for a Nuclear or Radiological Emergency, GSG2, jointly sponsored by the FAO, IAEA, ILO, PAHO, and WHO (IAEA, 2011).

The Safety Guide GS-G-2.1 provides guidance on different elements of the GS-R-2 Requirements, including concept of operations for different types of emergencies; sizes of emergency planning zones; examples of typical threat categories of practices, determining the quantity of radioactive materials that should be considered dangerous and plain language explanation of the risks to the public and emergency workers; emergency classes for emergencies at facilities; response time objectives; description of emergency facilities and locations; overview of urgent protective actions and other response actions. 
The recommendations presented in the Safety Guide GSG-2 concern the values of the generic criteria needed to develop operational criteria for implementing protective actions and other response actions to protect emergency workers and the public in the event of a nuclear or radiological emergency. Generic criteria are established as doses at which to take protective actions if projected, and medical response actions if received. They are based on consideration of a wide range of conditions that would prevail in an emergency. However, they are not directly measurable, hence the use of operational criteria is important.

Operational criteria are presented in the form of Emergency Action Levels (EALs) and Operational Intervention levels (OILs). EALs are specific, predetermined, observable plant criteria used for classification of an emergency and as a trigger for decisions on the implementation of precautionary urgent protective actions. OILs are typically expressed in terms of dose rates, ground or surface concentrations, or activity concentration of radionuclides in the environment, food or water samples. The OIL is a calculated quantity that corresponds to one of the generic criteria. If the OILs are exceeded, the appropriate protective action should be promptly taken. Examples of default operational criteria for implementing protective actions and other response actions are provided in the Safety Guide GSG-2. Decision makers in an emergency and the public may have only a limited or no understanding of the principles of radiation protection, the risks associated with radiation exposure and the appropriate actions that can be taken to reduce these risks. This Safety Guide therefore also provides a plain language explanation of the operational criteria, to assist in the communication of the purpose of each of the criteria and the associated protective actions and other response actions.

Table I gives generic criteria for acute doses for which protective actions and other response actions are expected to be undertaken under any circumstances to avoid or to minimize severe deterministic effects. If the dose is projected to be received, precautionary urgent protective actions have to be taken immediately (even under difficult conditions) to keep doses below these generic criteria. If the dose above these generic criteria has been received, immediate medical examination, indicated treatment and consultation have to be taken.

For uniform external whole body exposure to strongly penetrating radiation, the RBE weighted dose in red marrow is used as representative of the average RBE weighted dose to internal organs or tissues (e.g. red marrow, lung, small intestine, gonads, and thyroid) and to the lens of the eye. In the case of local exposure of soft tissue, the criteria are applied to the minimal dose in an area of $100 \mathrm{~cm}^{2}$ at a depth of $0.5 \mathrm{~cm}$ under the body surface. In case of contact exposure of skin, the criteria are applied to minimal dose in area of more than $100 \mathrm{~cm}^{2}$ of skin derma at a depth of $40 \mathrm{mg} / \mathrm{cm}^{2}$ under the skin surface. A 30-day committed RBE weighted dose in organ or tissue is used for characterizing internal exposure. The exception is exposure of the foetus, for which the period of in utero development is used for generic criteria. For the inhalation intake of radioactive material, the criteria are applied to 30-day committed RBE weighted dose to the alveolar-interstitial region of respiratory tract. 
Table I

Generic criteria for acute doses for which response actions are to be undertaken under any circumstances to avoid or to minimize severe deterministic effects.

\begin{tabular}{cll}
\hline & Organ & RBE weighted dose in organ \\
\cline { 2 - 3 } $\begin{array}{c}\text { External acute } \\
\text { exposure for less than } \\
10 \text { hours }\end{array}$ & Red marrow & $1 \mathrm{~Gy}$ \\
& Foetus & $0.1 \mathrm{~Gy}$ \\
& Soft tissue & $25 \mathrm{~Gy}$ at $0.5 \mathrm{~cm}$ \\
& Skin & $10 \mathrm{~Gy}$ to $100 \mathrm{~cm}^{2}$ \\
\hline \multirow{3}{*}{$\begin{array}{c}\text { Internal exposure from } \\
\text { acute intake }\end{array}$} & Organ & Committed RBE weighted dose in organ \\
\cline { 2 - 3 } & Red marrow & $0.2 \mathrm{~Gy}$ for radionuclides with $\mathrm{Z} \geq 90$ \\
& Thyroid & $2 \mathrm{~Gy}$ for radionuclides with $\mathrm{Z} \leq 89$ \\
& Lung & $2 \mathrm{~Gy}$ \\
& Colon & $20 \mathrm{~Gy}$ \\
& Foetus & $0.1 \mathrm{~Gy}$ \\
\hline
\end{tabular}

Table II provides a set of generic criteria (expressed in terms of projected dose and received dose) for use in the protection strategy that are compatible with reference levels (expressed in terms of residual dose) within a range of $20-100 \mathrm{mSv}$ recommended by the ICRP (ICRP, 2007) and provides details of specific protective actions and other response actions in different time frames.

Table II

Generic criteria for protective actions and other response actions in emergency exposure situations to reduce the risk of stochastic health effects.

\begin{tabular}{lll}
\hline & Generic criteria & Example response actions \\
\hline & \multicolumn{2}{c}{$\begin{array}{c}\text { Projected dose that exceeds the following generic criteria: } \\
\text { Take urgent protective actions and other response actions }\end{array}$} \\
\hline$H_{\text {Thyroid }}$ & $50 \mathrm{mSv}$ in the first 7 days & Iodine thyroid blocking \\
$E$ & $100 \mathrm{mSv}$ in the first 7 days & $\begin{array}{l}\text { Sheltering, evacuation, decontamination, restric- } \\
\text { tion of food, milk and water consumption }\end{array}$ \\
$H_{\text {Fetut }}$ & $100 \mathrm{mSv}$ in the first 7 days & $\begin{array}{l}\text { Projected dose that exceeds the following generic criteria: } \\
\text { Take early protective actions and other response actions }\end{array}$ \\
\hline$E$ & $100 \mathrm{mSv}$ in the first year & $\begin{array}{l}\text { Temporary relocation, decontamination, replace- } \\
\text { ment of food, milk, and water }\end{array}$ \\
$H_{\text {Fetus }}$ & $100 \mathrm{mSv}$ in period of in utero & \\
\hline
\end{tabular}

Received dose that exceeds the following generic criteria:

Take longer term medical actions to detect and to effectively treat radiation induced effects

\begin{tabular}{lll}
\hline$E$ & $100 \mathrm{mSv}$ in the first month & $\begin{array}{l}\text { Screening based on equivalent doses to specific } \\
\text { radiosensitive organs (as a basis for medical } \\
\text { follow-up), basic counselling }\end{array}$ \\
$H_{\text {Fetus }}$ & $\begin{array}{l}\text { Counselling to allow informed decisions to be } \\
\text { development }\end{array}$ & $\begin{array}{l}\text { made in individual circumstances } \\
\text { mSv in period of in utero }\end{array}$ \\
\hline
\end{tabular}


Table III recommends guidance values to be used for the protection of emergency workers responding to an emergency. The Safety Guide specifies an emergency worker as a person having specified duties as a worker in response to an emergency, who might be exposed while taking actions in response to the emergency. Emergency workers may include those employed by registrants and licensees as well as personnel from response organizations, such as police officers, firefighters, medical personnel, and drivers and crews of evacuation vehicles.

\section{Table III}

Guidance values for restricting exposure of emergency workers.

\begin{tabular}{cc}
\hline Tasks & Guidance value $^{\mathrm{a}}$ \\
\hline Life saving actions & $H_{p}(10)^{\mathrm{b}}<500 \mathrm{mSv}$
\end{tabular}

This value may be exceeded under circumstances which the expected benefits to others clearly overweigh the emergency worker's own heath risks, and the emergency worker volunteers to take the action and understands and accepts this health risk

Actions, to prevent severe $\quad H_{p}(10)<500 \mathrm{mSv}$ deterministic effects and

actions to prevent the development of catastrophic conditions that could significantly affect people and the environment

Actions to avert a large collective dose $H_{P}(10)<100 \mathrm{mSv}$

a These values apply only for the dose from exposure to external penetrating radiation. Doses from exposure to non-penetrating external radiation and from intake or skin contamination need to be prevented by all possible means. If this is not feasible, the effective dose and the equivalent dose to an organ that are received have to be limited to minimize the health risk to the individual in line with the risk associated with the guidance values given here.

${ }^{\mathrm{b}} H_{P}(10)$ is the personal dose equivalent $H_{P}(d)$ where $d=10 \mathrm{~mm}$.

In addition to the Safety Requirements and Safety Guides, technical guidance and operational manuals are developed to support their implementation. They are covering wide range of technical issues addressing the needs of emergency planners and responders. Through regional and national training events using standardized training materials, the IAEA effectively makes information available to Member States and assists them in applying guidance.

\section{Conclusions}

IAEA Safety Standards and guidance in the area of emergency preparedness and response aim to assist in strengthening national response capabilities and arrangements. Their application facilitates communication in an emergency and contributes to harmonization of national criteria for protective and other actions. 


\section{REFERENCES}

IAEA (1987) Convention on early notification of a nuclear accident, and Convention on assistance in the case of a nuclear accident or radiological emergency, Legal Series No. 14, 1987.

IAEA (2002) Preparedness and Response for a Nuclear or Radiological Emergency, Safety Standards Series No. GS-R-2, 2002.

IAEA (2007) Arrangements for Preparedness for a Nuclear or Radiological Emergency, Safety Standards Series No. GS-G-2.1, 2007.

IAEA (2011) Criteria for Use in Preparedness and Response for a Nuclear or Radiological Emergency, Safety Standard Series No. GSG-2, 2011.

ICRP Publication 103 (2007) The 2007 Recommendations of the International Commission on Radiological Protection, Ann. ICRP 37 (2-4).

McKenna T., Buglova E., Kutkov V. (2007) Lessons learned from Chernobyl and other emergencies: establishing international requirements and guidance, Health Physics, 93 (5), 527-537. 